\title{
L'aportació del Gazophylacium catalano-latinum, de Joan Lacavalleria, a la terminologia catalana
}

\author{
Pere Montalat \\ Institut d'Estudis Catalans \\ pmontalat@iec.cat \\ https://orcid.org/OOOO-OOO2-IOg6-2428 \\ Received: 05/04/2017; accepted 03/o7/2OI7 \\ DOI: https://doi.org/IO.7203/MCLM.4.IOO63
}

Contribution of Joan Lacavalleria's Gazophylacium Catalano-Latinum to Catalan terminology

Abstract

The publication in I696 of the Catalan-Latin dictionary Gazophylacium Catalano-Latinum by Joan Lacavalleria led to the incorporation into Catalan of a large number of technical terms, in spite of the early modern sociocultural context being unfavourable to scientific and technical developments. The Gazophylacium is the Catalan version of a French-Latin dictionary, Le Dictionaire [sic] royal augmenté by François-Antoine Pomey. Therefore, Lacavalleria may be considered as initiator of the systematic transfer procedure of terminological units of French origin into Catalan, which were also adopted by many other languages of culture until well into the twentieth century, and that favored the circulation of internationalisms. This article mainly describes the terminological units transferred from the French source into Catalan, examines the main proceedings of terminological formation and the adapting process of French terms into Catalan and, lastly, it accounts for the reception and subsequent implementation of these terms.

KEYWORDS

Joan Lacavalleria; Gazophylacium Catalano-Latinum; dictionaries; specialized vocabulary; terms; technical terms; loanwords.

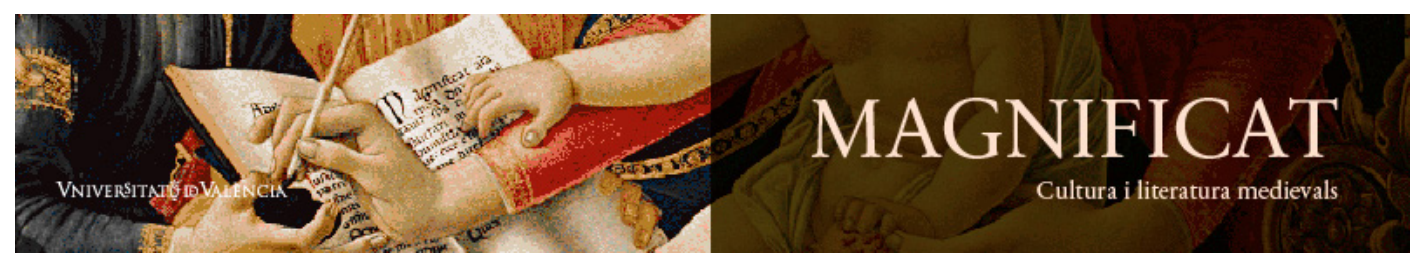

Magnificat Cultura i Literatura Medievals 4, 20I7, 93-105. http://ojs.uv.es/index.php/MCLM

ISSN 2386-8295 
RESUM

En un context sociocultural poc favorable al desenvolupament científic i tècnic, la publicació, l'any i696, del diccionari català-llatí Gazophylacium catalano-latinum de Joan Lacavalleria va suposar paradoxalment la incorporació al català d'un gran nombre de termes d'especialitat. El Gazophylacium és la versió catalana d'un diccionari francès-llatí, Le dictionaire [sic] royal augmenté de François-Antoine Pomey. Es pot considerar, doncs, que Lacavalleria va ser l'iniciador del procediment de transferència o naturalització sistemàtica d'unitats terminològiques d'origen francés al català, procediment que, al seu torn, també fou adoptat per moltes altres llengües de cultura fins ben entrat el segle XX i que va afavorir la difusió dels internacionalismes. L’objectiu principal d'aquest article és descriure la tipologia de les unitats terminològiques transferides del model francès al català, examinar els principals procediments de formació terminològica així com el procés d'adaptació dels termes francesos al català i, per últim, donar compte de la recepció i la implantació posterior dels dits termes.

PARAULES CLAU

Joan Lacavalleria; Gazophylacium catalano-latinum; diccionaris; vocabulari especialitzat; termes; tecnicismes; manlleus.

Pere Montalat. 2017. 'L'aportació del Gazophylacium catalano-latinum, de Joan Lacavalleria, a la terminologia catalana', Magnificat Cultura i Literatura Medievals, 4: 93-IO5

\section{TAULA DE CONTINGUTS}

I Introducció - 95

2 El vocabulari especialitzat del Gazophylacium catalano-latinum - 96

2.I Transferència de tecnicismes ben implantats en francès - 96

2.2 Transferència de neologismes del francès - 99

2.3 Mancances en l'estructura conceptual dels tecnicismes transferits - IOO

3 Recepció i implantació de la terminologia del Gazophylacium - IO2

4 Conclusió - IO4

5 Obres citades - IO5 


\section{b米}

\section{Introducció}

L'historiador Ernest Lavisse (I9O5: I72-I84) explica que la primera meitat del segle XVII és plena d'esdeveniments molt considerables per a la història de la ciència. De la seva extensa relació, en reportem alguns a manera d'exemple. L'any i6ro Galileo Galilei publicà l'obra Sidereus nuntius, on, entre d'altres coses, anunciava que per mitjà d'una lent d'augment havia descobert espectacles inimaginables, com ara les muntanyes i les valls de la lluna, fins aleshores considerada llisa. El I6r9, Kepler va enunciar les lleis del desplaçament dels astres en l'espai a l'obra Harmonice mundi. El I628, William Harvey publicà un tractat sobre el moviment del cor i de la sang en els animals, Exercitatio anatomica de motu cordis et sanguinis in animalibus. L'any I637, René Descartes publica en francès el Discours de la méthode, obra que va acompanyada per tres tractats, la Dioptrique, Météores i la Géométrie, que es presenten com assajos del mètode. Però el fet més destacat de tots és que Descartes va ser capaç de concebre la unitat de la ciència i li va fornir un mètode universal que és vigent encara avui.

Aquesta florida extraordinària de les ciències a d'altres parts d'Europa contrasta amb el que s'esdevenia a la mateixa època a Catalunya i a Espanya que, com han explicat els historiadors de la ciència (Agustí I983: I-3), en van quedar al marge. En efecte, la política d'aïllament que arrenca amb el regnat de Felip II, juntament amb una greu crisi econòmica i social, no va afavorir el conreu de les ciències. Així, la pobra cultura científica del segle XVII a casa nostra es va limitar a l'ensenyament de les matemàtiques impartit a l'escola dels jesuïtes.

Amb tot, l'any i696 es publicà el Gazophylacium catalano-latinum, que és obra de Joan Lacavalleria. Es tracta d'un diccionari català-llatí orientat a l'aprenentatge d'aquesta segona llengua que, paradoxalment, acull nombrosos termes cientificotècnics, molts dels quals són primeres documentacions en català, fet que no ha passat desapercebut als estudiosos que s'han interessat per aquesta obra (Colón-Soberanas I986: IIO-II2).

Home de lleis i de lletres, Lacavalleria fou doctor en dret canònic i en dret civil i es dedicà professionalment a l'advocacia. En l'àmbit de les lletres, publicà dues obres: el diccionari llatícastellà de veus poètiques Bibliotheca musarum, l'any I68I, i el Gazophylacium ja dit. Amb aquesta darrera obra Lacavalleria pretenia superar els diccionaris català-llatí dels seus predecessors immediats, Antoni Font i Pere Torra, perquè "si bé lo Fons verborum y lo Vocabulari de Torra són llibres molt erudits, totavia se troban tant succints que en ells falta un número casi innumerable de vocables, y tant poc exornats que contenen poques frases no solament per a la composició, sinó y també per a variar-la" (Lacavalleria I696: IV).

En un article recent (Montalat 2OI5a), hem fet saber que la font principal del Gazophylacium és el diccionari francès-llatí Le Dictionaire [sic] royal augmenté del pare jesuïta François-Antoine Pomey, publicat l’any i67r a Lió. Per ser ben precisos, el Gazophylacium n'és la versió catalana.

El diccionari del pare Pomey és una obra d'orientació pedagògica, destinada als alumnes de retòrica dels col-legis jesuïtes, i, com informa el títol, es tracta de l'edició ampliada d'un diccionari francès-llatí anterior. Aquesta obra va gaudir d'una considerable difusió en l’àmbit de la lexicografia bilingüe i trilingüe de l'època, ja que se'n coneixen nombroses impressions no solament a França, on se’n comptabilitzen nou impressions, ${ }^{1}$ sinó també en altres països: n’hi ha una versió trilingüe

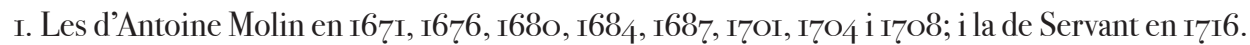


francès-llatí-alemany reimpresa a Alemanya almenys en deu ocasions, ${ }^{2}$ i una versió neerlandès-llatí amb no pas menys de quinze reimpressions. ${ }^{3}$

El racionalisme cartesià no solament va influir en la manera de dur a terme la ciència, també ho va fer en l'àmbit de la llengua a través d'una nova institució, l'Académie Française, que implantà un model de llengua classicitzant i racionalista, el bon usage (Suso 1996: I87). En aplicació de les mesures previstes pels defensors del bon usage, els diccionaris no podien incloure mots arcaics ni desuets, ni neologismes, ni estrangerismes, ni vocabulari d'arts i oficis, ni vocabulari tecnicocientífic, ni tampoc mots de registre baix o malsonant.

El diccionari del pare Pomey no segueix els criteris imposats pels defensors del bon usage i incorpora una gran quantitat de tecnicismes encunyats al segle XVI i la primera meitat del XVII. Tampoc segueix les consignes dels jesuïtes amb relació a Descartes, ja que, en teoria, la Companyia de Jesús prohibia l'ensenyança de les seves obres; però a la pràctica molts jesuïtes varen adoptar una actitud eclèctica: si bé, d'una banda, assumien la prohibició d'ensenyar la part doctrinal, filosòfica i teològica de l'obra cartesiana, d'una altra, es mostraven força més receptius a l'hora d'incorporar-ne les novetats científiques, com veurem tot seguit.

\section{El vocabulari especialitzat del Gazophylacium catalano-latinum}

$\mathrm{M}$ olts dels tecnicismes que figuren en el diccionari del pare Pomey foren transferits al català a través del Gazophylacium, i es poden datar a partir de la informació que la seva font francesa ens forneix (Montalat 20I5b: 374-378). Bona part dels mots i accepcions d'especialitat del diccionari de Lacavalleria foren encunyats en francès en el segle XVI i la primera meitat del XVII, i en el moment de la publicació del diccionari de Pomey ja havien arrelat; però n'hi ha d'altres, d'aparició més recent, sorgits a la segona meitat del segle XVII, que encara no havien assolit un grau d'estabilitat suficient dins del sistema de la llengua francesa, i que apareixen per primer cop en un diccionari. Per aquest motiu, Pomey sent la necessitat d'indicar-ho i de justificar-ne la inclusió mitjançant una llista que precedeix el seu diccionari.

A continuació, oferim una selecció dels tecnicismes transferits per Lacavalleria que ens han semblat representatius de l'època i de la mena d'obra que ens ocupa.

\section{I Transferència de tecnicismes ben implantats en francès}

D'entre els mots que ja s'havien consolidat en la llengua francesa, destaquen molt especialment els que fan referència a les ciències de l'observació: il-lustrem la nostra selecció amb termes que pertanyen al camp de les ciències naturals, de l'anatomia, de la física i de l'astronomia, però també amb termes de l'àmbit de l'hípica i d'estratègia militar.

En l'àmbit de les ciències naturals, sorgeix la necessitat de descriure i classificar els éssers vius amb criteris científics. Lacavalleria recull les denominacions insecte (fr. insecte) i amfíbio (fr.

2. Le Grand Dictionnaire royal, I. François-latin-alleman. II. Latin-alleman-françois. III. Alleman-françois-Latin, cidevant composé par le R. P. François Pomai (168I), Frankfurt, Zubrodt [Bencard 169o, I700, 1709, 1715, 1730; Noethen I733, 1740 ; s. e. 1743 ; Rieger 1767$]$.

3. Novum Dictionarum belgico-latinum, ex optimis authorum monumentis et praesertim e Dictionario regio R. P. Francisci Pomey concinnatum (1717), Maastricht: Lambertus Bertus [1728; Lekens I739, I753, $c a$. I764, I769, I776, $c a$. I780, I795; Verdussen I74I, I752, I760, I769, I777; Granje I762]. 
amphibie) amb la informació següent:

INSECTE. Hoc insectum, ti. Anomenanse insectes (diu Plinio) certs petits animals, los quals al lloch de membres tenen unes menudes incisions y entretalls.

AMFÍBIO. Amphibius, a, um. Animals amfibios, que viuhen dessota de la terra y dins de la aygua.

Es produeixen avenços notables en el camp de l'anatomia. Cal donar compte de la morfologia dels éssers vius, de la seva estructura interna. Així, es posen en pràctica noves tècniques, com la dissecció i la transfusió de sang. Lacavalleria importa els termes estructura (fr. structure), dissecció (fr. dissection) i transfusió (fr. transfusion) amb la informació següent:

ESTRUCTURA. Haec structura, ae. Haec constructio, onis. Haec fabrica, ae. Haec extructio, onis. Haec fabricatio, onis. Que admirable és la estructura de totes les parts del nostre cos!

DISSECCIÓ, en fet de anatomia. Haec dissectio, onis. Fer la dissecció del cos o de un membre de algun animal. Dissecare corpus aut membrum alicuius animalis.

TRANSFUSIÓ. Haec transfusio, onis.

El mot transfusió és recollit sense definició ni exemples i únicament se n'indica l'equivalència llatina. Aquest procediment no és imputable al nostre autor, sinó a la font francesa, que dóna la mateixa informació. Pel que fa a aquest mot, és força probable que Lacavalleria no en conegués altra cosa més enllà del significat genèric del mot llatí: transfusio, 'transvasament'. No tenim cap explicació de per què Pomey va ser tan lacònic a l'hora de recollir aquest terme. En canvi, podem aventurar quin era el sentit i l'ús que tenia en ment a l'hora d'incloure'l en el diccionari.

El terme francès transfusion es documenta per primer cop amb la forma transfusion de sang a la revista Journal des Sçavans de 3i de gener de i667. Aquest terme apareix en el report d'un experiment de transfusió de sang entre dos gossos, dut a terme per Richard Lower a Anglaterra. I és força probable que Pomey espigolés el terme d’aquella publicació, ja que el Journal és una de les obres que va buidar sistemàticament, com diu a la nota adreçada al lector que precedeix el seu diccionari.

En l'àmbit de la física, es difonen noves teories que volen donar compte de les lleis físiques del moviment. Així, Descartes, a l'obra Les principes de la philosophie, per explicar per què un cos llançat enlaire torna a caure a terra, encunyà el terme vertu attractive, traslladat al català per virtut atractiva,${ }^{4}$ mitjançant el qual volia significar que la terra té una força que actua com un imant $\mathrm{i}$ atrau els cossos:

ATRACTIU, lo que atrau ab alguna violència. Attractionis potens, (tis). Attrahendi efficax, (cis). Attrahendi vim habens, (tis). Attrahendi vi praeditus, a, um. Virtut atractiva. Attrahendi vis, (is). Attrahendi facultas, (atis). Atractiu, lo que atrau afalagant. Blandus, a, um. Illecebrosus, a, um.

L’astronomia, a més de determinar el nombre, la composició i el moviment dels cossos celestes,

4. Tot i que l'adjectiu atractiu ja es documenta a Arbre de ciència, de Ramon Llull, amb el sentit de 'potència o força que atrau', en el Gazophylacium apareix formant part del terme plurilexemàtic virtut atractiva, el qual pertany a l'àmbit especialitzat de la física i era emprat aleshores per a designar el que avui es coneix com a 'força de la gravetat'. 
pretenia en última instància explicar el sistema de l'univers. En relació amb aquest àmbit, el Gazophylacium acull els mots meteoro (fr. météore) i sistema (fr. système), els quals, si bé no eren novetats absolutes en francès, Descartes va posar en voga, especialment el primer, arran de la publicació de la seva obra Météores, dedicada a aquests fenòmens físics:

METEORO. Hoc meteorum, ri. Los meteoros són certs cossos imperfets composts dels vapors y de les exhalacions que lo Sol ab son calor atrau en alt.

SISTEMA. Hoc systema, ae.

Probablement, Pomey va incloure système pensant en el sentit astronòmic que té el mot en el títol de l'obra de Galileo Dialogo sopra i due massimi sistemi del mondo Ptolemaico e Copernico, i que cita Descartes, en francès: "système du monde".

La nova recerca no és especulativa sinó aplicada. L’observació del món, "tant d’allò que és infinitament petit com del que és infinitament gran", per dir-ho amb paraules de Lavisse (I905: 284), fou possible gràcies a un instrumental que de Galileo ençà esdevenia cada cop més precís i potent. Ens referim al microscopi, també anomenat aleshores engiscopi, que Lacavalleria trasllada amb les denominacions de engiscopo (fr. engyscope) i microscopo (fr. microscope):

ENGISCOPO, instrument per a vèurer de prop les coses petites y per a engruxir-les. Hoc engyscopium, pii.

MICROSCOPO, instrument matemàtich per a vèurer los petits cossos. Hoc microscopium, ii.

Com acabem de veure, els mots importats són majoritàriament d'origen grecollatí. Lacavalleria es trobava especialment còmode traduint mots francesos d'arrel llatina o grega passada pel llatí, i la translació al català es produeix sense gaire entrebancs. Vegeu, a continuació, els procediments d'adaptació seguits:

* Manlleus adaptats gràficament: amfibio (del fr. amphibie), en què el grup -ph-passa a -f-; virtut atractiva (del fr. vertu attractive), en què el grup -tt- es redueix a -t-; i sistema i engiscopo, on la $-y$-grega passa a $-i$ - llatina.

* Manlleus adaptats morfològicament: estructura (del fr. structure) i sistema (del fr. système), en què els mots femenins terminats en -e caduca s'adapten amb - $a$; amfibio (del fr. amphibie), meteoro (del fr. météore), engiscopo (del fr. engyscope) i microscopo (del fr. microscope), on els mots masculins terminats en -e caduca són reforçats amb una -o final; dissecció (del fr. dissection) i transfusió (del fr. transfusion), en què el sufix -tion s'adapta regularment en -ció i el sufix -ion ho fa en -ió.

* Manlleus adaptats fonèticament: estructura (del fr. structure), on la $s$-inicial francesa s'adapta a la fonètica catalana mitjançant l'adjunció d'una $e$ - de suport.

En general, els diccionaris elaborats pels jesuïtes no incloïen mots d'arts i oficis ni tecnicismes, i en això cal reconèixer que el diccionari del pare Pomey és una excepció; però, en canvi, sí que admetien mots d'àmbits especialitzats considerats nobles, com ara l'heràldica, la cinegètica, l'hípica, la guerra i l'estratègia militar. Lacavalleria no va traslladar gairebé cap terme d'heràldica ni de cinegètica. Els mots d'aquestes disciplines presenten unes idiosincràsies pròpies de la llengua 
francesa que feien de mal traduir al català. Sí que en trobem, en canvi, d'hípica, com corbeta (fr. courbette) i isabelle, que fa referència al color marró clar dels cavalls:

CORBETA, saltet que sab fer lo cavall adestrat. Crurum in sublime porrectorum alternis solum ferientium numerosa glomeratio, (onis). Aqueix cavall fa les corbetes molt compassades.

ISABELLE. Color isabelle, color de palla. Gilvus color, (oris). Color melinus. Color ex albo rutilans.

En l'àmbit de la guerra i de l'estratègia militar, documentem tecnicismes com ara càrrega (fr. charge), contrabateria (fr. contre-baterie) i escarpa (fr. escarpe):

CÀRREGA [...] Càrrega, obra de acomètrer al enemich. Haec aggressio, onis. Haec impressio, onis. In hostem irruptio, (onis). In hostem incursio, (onis). In hostem impressio, (onis). Tocar la càrrega, fer lo senyal per a acomètrer al enemich. Canere bellicum. Canere classicum. Praelii dare signum. Anar a la càrrega dels enemichs, dar la càrrega als enemichs. In hostiles copias irrumpere.

CONTRABATERIA (en térmens de guerra). Staturae adversus machinas bellicas aliae machinae, (arum). Tormentis adversa tormenta, (orum). La contrabateria causava gran dany als assitiadors.

ESCARPA, fortificació. Muralis fossae interior lorica, (ae). Muralis fossae intimus agger, (eris). Ad ima muri vallum, (li). Intimae ad murum fossae munita crepido, (inis). Intimae ad murum fossae vallatus agger. Munir o fortificar un fosso de una escarpa. Intimum fossae labrum lorica munire.

En l'adaptació dels termes d'hípica, de guerra i d'estratègia militar Lacavalleria no mostra la mateixa seguretat amb què adapta els del primer grup. La raó és que aquests darrers són d’arrel francesa.

* Manlleu directe no adaptat: isabelle (del fr. isabelle).

* Manlleu adaptat a la fonètica francesa: corbeta (del fr. courbette), en què el grup -ou-, pronunciat $[\mathrm{u}]$, passa a -o-, pronunciat $[\mathrm{u}]$ en els parlars del català central.

* Calc semàntic: càrrega (del fr. charge) pres en el sentit militar de 'atac a l'enemic'.

* Manlleus adaptats morfològicament: contrabateria (del fr. contre-baterie) i escarpa (del fr. escarpe, pres, al seu torn, de l'italià scarpa), en què la -e caduca s'adapta amb - $a$.

\subsection{Transferència de neologismes del francès}

D'entre els tecnicismes importats per Lacavalleria, n’hi ha que són de creació més recent. Es tracta d'un grup de termes encunyats a la segona meitat del segle XVII. La particularitat d'aquests mots ve del fet que aleshores encara no estaven prou fixats en el sistema de la llengua francesa ni havien aparegut en cap diccionari. Són, per dir-ho amb paraules de Pomey, "mots françois tirez du latin et nouvellement introduits", és a dir, 'mots creats a partir del llatí i introduïts recentment'. Ara en diríem 'neologismes'.

Hi ha un altre aspecte que m’interessa ressaltar a propòsit d'aquests mots, i és que a diferència dels del grup anterior, que procedeixen o bé del grec i del llatí o bé del francès, aquests són 
exclusivament d'origen llatí. La raó d'aquest canvi d'orientació radica molt probablement en les prescripcions de l'Académie, que no era partidària d'admetre neologismes, però que, en cas de necessitat, recomanava de recórrer al llatí.

Naturalment, Lacavalleria no era coneixedor de les discussions de l'Académie sobre el model de llengua i, per tant, en el moment de transferir lèxic francès al català, no era conscient de cap d'aquestes consideracions. Però això no va ser obstacle perquè el nostre autor importés un nombre sorprenentment elevat d'aquells mots. Som del parer que hi va ajudar, i molt, el fet que la base lèxica dels mots transferits fos d'arrel llatina. A un llatinista com ell, això segurament li devia produir molta tranquil-litat.

Entre els tecnicismes importats per Lacavalleria n'hi ha un bon nombre de l'àmbit del dret, com ara abdicació de un càrrech (fr. abdication d'une charge) i perpetrar un crim (fr. perpétrer):

ABDICACIÓ de un càrrec. Muneris abdicatio, (onis). Fer abdicació de un càrrech. Munus abdicare, reiicere.

PERPETRAR un crim. Crimen patrare vel perpetrare vel committere.

El verb perpetrar, documentat en els escrits lul-lians en l'expressió perpetrar un pecat, ${ }^{5}$ i en Lo somni de Bernat Metge en l'expressió perpetrar actes luxuriosos, fou registrat per Lacavalleria en la construcció que avui ens és familiar de perpetrar un crim.

També n'hi ha de l'àmbit de l'astronomia, orbe (fr. orbe) i de química, laboratori de chímica (fr. laboratoire de chimique):

ORBE, círculo. Hic orbis, is. Los orbes dels set planetes. Septenorum planetarum orbes, (ium). V. Món.

LABORATORI de chímica, oficina per a treballar a la chímica. Chimica officina, (ae).

Com en el cas dels altres mots d'origen llatí ja vistos, la transferència de mots francesos d'arrel llatina al català es produeix regularment i sense entrebancs:

* Manlleus adaptats morfològicament: abdicació (del fr. abdication), en què el sufix -ation passa a -ció; i perpetrar (del fr. perpétrer), en què la terminació -er del francès passa a -ar en català.

* Manlleus adaptats fonèticament: orbe (del fr. orbe), on la $e$ caduca del francès s'adapta a la fonètica catalana mitjançant la pronuncia [ə] en català oriental; i laboratori (del fr. laboratoire), en què el so [wa] s'adapta a la fonètica catalana com a [o].

\subsection{Mancances en l'estructura conceptual dels tecnicismes transferits}

Malgrat que Lacavalleria enriqueix notablement el català, cal admetre mancances en l'estructura conceptual del vocabulari transferit. Per evidenciar-ho, hem elaborat l'arbre de camp de l'òptica, que era la part de la física més avançada al segle XVII. Per fer-ho ens basem en el que forneix el mateix

5. Miquel Colom (I982), s.v. PERPETRAT -ADA, aporta el context següent extret de l'obra La doctrina dels infants, f. 7or: "Lo primer sagrament de la sancta sgleya és batisma, lo qual leva [sic] e munde hom de peccat original, lo qual peccat fou perpetrat per nostre pare adam e per nostra mare eva". 
Pomey en una altra de les seves obres, l'Indiculus universalis o 'índex universal', publicada l'any I667. Es tracta d'un manual escolar de caire lexicogràfic i enciclopèdic, on els mots s'ordenen temàticament.

En aquesta obra, l'òptica es defineix com a formant part d'una branca més ampla del coneixement, les matemàtiques. L'òptica considerada com a disciplina es divideix en tres branques: l’òptica, que és alhora el terme genèric de la disciplina, la catòptrica i la diòptrica:

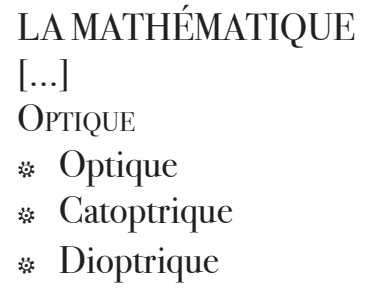

En el diccionari de Pomey aquests tres termes es tracten de la manera següent:

OPTIQUE, partie de la mathématique. Haec optica, ae. Haec optice, es. Aspectus aspectabiliumque scientia. Appartenant à l’optique. Opticus, a, um.

L'optique traite de la veue en général et de tout ce qui se voit par le rayon droit. Elle explique la nature et les proprietéz de la veue et l'endroit de l'oeil où elle se fait. [...]

Elle donne les raisons pourquoy les choses paroissent à nos yeux tantôt plus grandes, tantôt plus petites, tantôt plus distinctes, tantôt plus confuses, tantôt plus proches, tantôt plus éloignées. $[\ldots]$

Elle montre comme quoy quelques-uns ne voyent que de bien près et les autres ne voyent que de loin; pourquoy l'oeil ne se peut pas voir soy-mesme et d'où vient que nos deux yeux ne voyent pas deux objets mais un seul. [...]

Elle découvre les causes de la tromperie de nostre veue, pourquoy les objets éloignéz paroissent plus petits qu'ils ne sont; pourquoy deux lignes parallèles semblent s'approcher dans la distance, pourquoy les objets à plusieurs angles paroissent ronds de loin, etc.

CATOPTRIQUE, partie de l'optique. Haec catoptrica, ae.

La catoptrique traitte du rayon refleschi et donne les règles et les causes des reflections differentes selon la diversité des corps où elle se fait. [...] En particulier, elle traitte de toute sorte de miroirs, des plains, des convexes, des concaves, des paraboliques, des elliptiques, des hyperboliques, des miroirs ardents.

DIOPTRIQUE, partie de l'optique. Haec dioptrica, ae.

La dioptrique parle de la réfraction et en donne les règles. Elle enseigne la manière de faire toute sorte de lunettes, des engyscopes, des microscopes et d'autres tels instruments qui servent à grossir ou à diminuer, à approcher ou à éloigner les objets.

En primer lloc, Pomey defineix l'objecte general de l'òptica i, a continuació, explica les particularitats d'aquesta disciplina. La catòptrica i la diòptrica es defineixen com a parts de l'òptica i, tot seguit, s'explica quin és el seu camp d'estudi.

Si comparem ara el tractament que dóna Lacavalleria als termes d'òptica en el Gazophylacium, comprovem que és força més incomplet. Per començar, no defineix l'àmbit d'estudi de l'òptica i manca la branca de la catòptrica. La diòptrica, en canvi, té un tractament força semblant a la del seu model: 


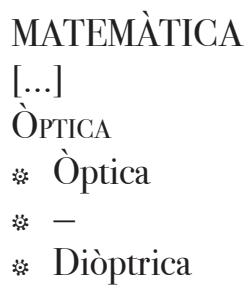

ÒPTICA, part de la matemàtica. Haec optica, ae. Haec optice, es. Aspectus aspectabiliumque scientia, (ae). Lo que pertany a la òptica. Opticus, a, um. V. Perspectiva.

DIÒPTRICA, part de la òptica. Haec dioptrica, ae. La diòptrica parla de la refracció y ne dóna les regles. Ella enseny a lo modo de fer tot gènero de ulleres, engiscopos, microscopos y altres semblants instruments que serveixen per a engrandir o disminuyr per a acostar o allunyar los objectes.

A diferència de Pomey, que presumiblement va tenir al seu abast l'obra de Descartes, $L a$ dioptrique, Lacavalleria només en tenia un coneixement indirecte. A manca dels textos originals, on els mots d'una disciplina donada queden instituïts com a termes científics, el nostre autor es va haver de conformar amb un coneixement de segona mà, que de vegades, com ja hem tingut ocasió de comentar, no és ni prou explícit ni prou intel-ligible.

\section{${ }_{3}$ Recepció i implantació de la terminologia del Gazophylacium}

$\mathrm{E}$ Gazophylacium no es va tornar a publicar. No sabem si va ser a causa del preu elevat d'una obra tan voluminosa, o bé si a causa de la guerra de Successió, que va capgirar tants aspectes de la vida d'aquest país. Fos com fos, el que sí que sabem és que aquest diccionari va tenir una llarga vida com a obra de referència per a l'aprenentatge del llatí fins ben entrat el segle XIX. ${ }^{6}$

Pel que fa al vocabulari científicotècnic contingut en aquest diccionari, caldrà esperar el segle XIX perquè comenci a ser valorat i se'n tregui rendiment d'una manera sistemàtica. Els encarregats de la seva difusió i divulgació van ser els lexicògrafs, que n’aprofitaren bona part del material per a l'elaboració dels seus diccionaris.

A continuació, comentem breument alguns aspectes que ens han semblat rellevants de l'aprofitament del Gazophylacium en el Diccionari de la llengua catalana amb la correspondència castellana de Pere Labèrnia, el "diccionari Labèrnia”, obra en dos volums publicats el I839 i I840, respectivament, on l'autor cita l'obra de Lacavalleria com a una de les seves fonts.

En el moment en què Pere Labèrnia elabora el seu diccionari, feia temps que a les escoles s'ensenyava la ciència positiva. Els professors que la impartien tenien accés a les principals teories científiques formulades els segles anteriors a través de traduccions o per via de tractats i manuals d'ús escolar que n'eren un compendi o, en el millor dels casos, s'havien format a l'estranger. I també hi havia institucions que fomentaven la investigació tècnica, com ara la Junta de Comerç, amb les seves escoles associades, i la Reial Acadèmia de Ciències Naturals.

Tot plegat feia que el bagatge de Labèrnia amb relació a la ciència i la tècnica modernes fos

6. Marià Aguiló (I825-1897) ens ha deixat un testimoni de l'ús del Gazophylacium com a obra de referència en el poema "Al lector" del seu poemari Records de jovenesa: D'infant, la llengua del Laci / m'ensenyava un reverend / a colps de Gazophilaci ... (Aguiló rgoo). 
infinitament millor que el de Lacavalleria, i, per tant, va ser capaç d'apropar-se al Gazophylacium amb un esperit crític notable, com veurem tot seguit.

Primer, manlleva els termes del Gazophylacium bo i ajustant-ne l'adaptació catalana, quan cal. Així, els vocables amfíbio i microscopo d'aquell diccionari passen a amfibi, que és la forma actual, i en el cas de microscopo, es manté la forma proposada per Lacavalleria, però la fa precedir de l'actual, microscopi:

AMFIBI. adj. Animal que viu en la terra y en la aygua. Anfibio. Anfibius.

MICROSCOPI Ó MICRÓSCOPO. $m$. Ullera que presenta los objectes mòltíssim mès grossos de lo que sòn. Microscopio. Microscopium, ï. [...]

Segon, Labèrnia comptava amb prou recursos per salvar els buits que hem tingut ocasió d'observar tant en el lemari com en les definicions de força mots del Gazophylacium. Per tant, s’aprecia una major consistència conceptual en la presentació del vocabulari especialitzat. Per exemple, les tres branques de l'òptica figuren en el diccionari Labèrnia d'una manera completa i amb definicions que s'ajusten a cadascun dels conceptes:

ÓPTICA.f. mat. Tractat del órgano y modo de la visió y dels raigs visuals. Óptica. Optica, ae.

CATÓPTRICA.f. Ciencia que tracta de las propietats de la llum refléxâ. Catóptrica. Catoptrica, $\alpha$.

DIÓPTRICA. f. Ciencia que demostra las propietats dels refractos de la llum y la formació dels cristalls óptichs. Dióptrica. Dioptrica, a.

Tercer, el contingut dels articles esdevé molt més explícit i clar que no pas en el Gazophylacium. Per exemple, l'article SISTEMA conté, entre d'altres, una accepció d'astronomia amb una definició, que manca en el Gazophylacium, on es dóna compte de les tres principals doctrines cosmològiques, la de Ptolomeu, la de Ticho Brahe i la de Copèrnic, l’heliocentrisme:

SISTEMA.f. [...] astr. La hipótesis que fan los astrónomos de cert orde y col-locació del univers, sobre lo fundament de la qual pretenen explicar los fenómenos que.s presentan á nostra vista: los tres principals sòn: lo de Tolomeo, lo de Ticon y lo de Coperni, lo que·ns posa lo cel immoble, que la terra es la ques mou, y es lo que está mès en boga en lo dia. Sistema. Systema, tis.

I quart, Labèrnia va incorporar en el seu diccionari el vocabulari de la ciència del seu temps. Això implica que certes expressions recollides en el Gazophylacium corresponents a un estadi anterior de la ciència en van quedar excloses. Posem, com a exemple, l'expressió encunyada per Descartes, vertu attractive, que és traslladada al Gazophylacium com a virtut atractiva. Al tombant del segle XVII la teoria cartesiana de l'atracció va quedar superada per la llei de la gravetat d'Isaac Newton (Mortureux 1973: 78). Labèrnia, dones, no va incloure l'expressió virtut atractiva, sinó atracció newtoniana:

ATRACCIÓ [...] atracciónewtoniana. La que-s verifica en las grans massas, en rahó de aquestas mateixas, y del quadrat de las distancias. Atracción neutoniana ó planetaria. Atractio newtoniana. 


\section{Conclusió}

Malgrat l'absència d'una labor terminogràfica tal i com l'entenem avui, devem a Lacavalleria la incorporació massiva de vocabulari especialitzat procedent del francès que és de base predominantment llatina i que, com hem vist, passa al català amb diversos graus d'adaptació morfològica, fonètica i gràfica. Per tant, el Gazophylacium prefigura els diccionaris catalans moderns, que acuden sistemàticament al francès per importar-ne el vocabulari tecnicocientífic.

El model de llengua imposat pels defensors del bon usage va afavorir la proliferació de tecnicismes d'arrel llatina, ja que, tot i no admetre neologismes, en cas d'haver-ne de crear, recomanaven aprofitar el cabal lèxic del llatí. Com a llatinista, Lacavalleria se sent còmode traslladant cultismes. En canvi, ja no se sent tan segur amb els mots d'arrel francesa i, per tant, o bé no els transfereix -és el cas del vocabulari d'heràldica- o bé, si ho fa, es mostra molt més dubitatiu quant a la seva adaptació gràfica i fonètica.

L'esforç dut a terme per Lacavalleria no va ser en va. El vocabulari especialitzat que va importar va quedar fixat i estabilitzat definitivament gràcies a la tasca de selecció i adaptació parcial duta a terme pels lexicògrafs del segle XIX. Un cop passats per aquest sedàs, constatem que aquells tecnicismes es varen vulgaritzar ràpidament sense perdre, per això, el sentit especialitzat originari. 


\section{${ }_{5}$ Obres citades}

Aguiló Fuster, Marian. I9oo. Recorts de jovenesa: poesies amoroses (Barcelona: Llibr. d’Àlvar Verdaguer).

Agustí i Cullell, Jaume. 1983. 'La introducció de la física clàssica a Catalunya en el segle XVIII', in his Ciència i tècnica a Catalunya en el segle XVIII: la introducció de la màquina de vapor, Arxius de la Secció de Ciències, 65 (Barcelona: IEC), p. I-72.

Colom Mateu, Miquel. I982. Glossari general lul.lià, 5 vols (Mallorca: Moll) [digitalitzat a Nou glossari general lul.lià, Centre de Documentació Ramon Llull de la Universitat de Barcelona $<\underline{\text { http://nggl.ub.edu/>] }}$

Colón, Germà; Soberanas, Amadeu-J. 1985. Panorama de la lexicografia catalana, Biblioteca Universitària, 7 (Barcelona: Enciclopèdia Catalana)

Lacavalleria i Dulac, Joan. I696. Gazophylacium catalano-latinum: dictiones phrasibus illustratas, ordine literario comprehendens: cui subjicitur irregularium verborum elenchus (Barcelona: Antoni Lacavalleria) $<\underline{\text { http: } / / \text { tinyurl.com/m72nj5y }>}$

Labèrnia, Pere. I839-I840. Diccionari de la llengua catalana: ab la correspondència castellana y Ilatina, 2 vols (Barcelona: Estampa dels hereus de la Viuda Pla) <http://tinyurl.com/kr7le8e $>$

Lavisse, Ernest. I9O5. 'L'Érudition et les sciences', in Histoire de France (Paris: Hachette), tome VIII: Le Gouvernement de l'intelligence, $172-\mathrm{I} 84$.

Montalat, Pere. 20I5a. 'La font francesa del Gazophylacium catalano-latinum de Joan Lacavalleria', Llengua \& Literatura, 25: 7-27 〈https://doi.org/IO.2436/20.2502.0I.7I $>$

Montalat, Pere. 2015b. 'Contribució a l'estudi del lèxic del Gazophylacium catalano-latinum de Joan Lacavalleria', Estudis Romànics, 37: 373-384 <https://doi.org/IO.2436/20.2500.0I.I79>

Mortureux, Marie-Françoise. I973. ‘À Propos du Vocabulaire scientifique dans la seconde moitié du XviIe siècle', Langue Française, I7: 72-80 $<$ http://tinyurl.com/kzcgyxj $>$

Pomey, François-Antoine. I680 [1671]. Le Dictionaire royal augmenté: Seconde édition enrichie d'un grand nombre d'expressions élégantes; de quantité de mots françois nouvellement introduits; des termes des arts, et de cinquante descriptions; comme aussi d'un petit traité de la vénerie et de la fauconnerie (Lyon: Antoine Molin) $\langle\underline{\mathrm{http}: / / \text { tinyurl.com/lqu6qx2 }>}$

Suso López, Javier. I996. 'Norme et bon usage au XvıIe siècle en France', in La lingüística francesa: gramática, historia, epistemología, ed. by Emilia Alonso, Manuel Bruña, and María Muñoz (Sevilla: Grupo Andaluz de Pragmática), I: I75-I88 